\title{
The posterior urethral valves revisited: embryological correlation, clinical classification, and risk stratification of the spectrum
}

\author{
Vivek Parameswara Sarma
}

\begin{abstract}
Background: The diagnosis of posterior urethral valves (PUV) encompasses a vast spectrum of disease with variable severity and clinical features. It is vital to understand the extent of developmental insult and to define the different distinct entities grouped together under the diagnostic umbrella of PUV. This would help to determine the severity of the disease, enable better prognostication, and optimize therapy. The objective of this study is to analyze the variable features of PUV and correlate the different manifestations with the embryological development of the urinary system. The possible developmental basis of anomalies in PUV is analyzed, as recognition of the underlying defect would help to determine the severity of the disease. A clinical classification and a risk stratification approach encompassing the spectrum of PUV is proposed, to help define diagnosis and guide prognosis. A combined retrospective and prospective analysis of cases diagnosed as PUV at the tertiary teaching institute over a 5-year period from July 2014 to July 2019 was done. The outcome of selected cases was analyzed, based on the risk group stratification.
\end{abstract}

Results: The incidence of major complications during follow-up in each risk group was assessed individually and found to be highest in the high-risk group (92\%), which was significantly higher than the other groups. The intermediate risk group was found to have a complication rate of 38\%, while the low-risk group had only $12.5 \%$ complication rate. The three key concepts addressed in this study pertain to the embryological basis of PUV, the necessity of a clinical subdivision of patients, and the possibility of risk stratification based on clinical criteria. The limited review of institutional series is added to highlight the method of risk stratification and its probable utility.

Conclusions: The most critical factors to be accounted for in the diagnosis and management of PUV are the definition of disease severity, recognition of systemic complications, and identification of children at risk of progression to ESRD. The proposed developmental defect analysis, description of PUV sequence, clinical classification, and risk stratification approach are only the means to this end of segregating patient groups within the diagnostic spectrum.

Correspondence: vivsarma@gmail.com

Department of Paediatric Surgery, Government Medical College,

Thiruvananthapuram, Kerala 695010, India

Springer Open (c) The Author(s). 2020 Open Access This article is licensed under a Creative Commons Attribution 4.0 International License, which permits use, sharing, adaptation, distribution and reproduction in any medium or format, as long as you give appropriate credit to the original author(s) and the source, provide a link to the Creative Commons licence, and indicate if changes were made. The images or other third party material in this article are included in the article's Creative Commons licence, unless indicated otherwise in a credit line to the material. If material is not included in the article's Creative Commons licence and your intended use is not permitted by statutory regulation or exceeds the permitted use, you will need to obtain permission directly from the copyright holder. To view a copy of this licence, visit http://creativecommons.org/licenses/by/4.0/. 


\section{Background}

The posterior urethral valves (PUV) are the commonest cause of congenital bladder outlet obstruction in male children and also the commonest obstructive cause of chronic renal failure (CRF) and end-stage renal disease (ESRD) in children [1]. The diagnosis of PUV encompasses a vast spectrum of disease with variable severity and clinical features. In its most severe form, the affection involves the entire urinary tract with considerable secondary systemic sequelae. It is vital to understand the extent of developmental insult and to define the different distinct entities grouped together under the diagnostic umbrella of PUV. This would help to determine the severity of the disease, enable better prognostication, and optimize therapy.

\section{Objective}

The objective of this study was to analyze the variable features of PUV and correlate the different manifestations with the embryological development of the urinary system. A clinical classification and risk stratification approach encompassing the spectrum of PUV is proposed, to help define diagnosis and guide prognosis.

\section{Methods}

The embryologic basis of the disorder in PUV was reviewed in detail. The abnormalities in different types of the disease were correlated with the possible developmental defect and its clinical consequence. A clinical classification and risk stratification approach to PUV is proposed based on the findings of clinical assessment, laboratory investigations, sonology, voiding cystourethrogram (VCUG), isotope study, and cystoscopy. This is done with the aim of precise identification of definite subgroups, to be utilized at diagnosis and during followup.

A targeted and specific review of the institutional series of PUV was done, with the specific objectives of clinical classification of the spectrum of PUV and stratification of patients into one of the risk groups proposed (high/intermediate/low). The aim was to correlate the specific risk group with the treatment received and complications during follow-up. The necessary institutional research and ethical approval were obtained. A combined retrospective and prospective analysis of cases diagnosed as PUV at the institute over a 5-year period from July 2014 to July 2019 was done.

The standard therapy followed was not influenced by the clinical classification or risk stratification, which were assigned only for the analysis based on available data. The outcome of selected cases was reviewed based on the risk group stratification. Exclusion criteria among all diagnosed cases of PUV during this period were (1) children older than 5 years at presentation (because many were referred after initial treatment at other centers and almost always had features of valve bladder/systemic complications), (2) patients presenting with CRF/ ESRD, (3) presence of multiple anomalies or co-existent urological problems like pelvi-ureteric junction obstruction/duplication/multicystic dysplastic kidney which would complicate assessment, and (4) lack of all necessary data for risk stratification.

The general institutional protocol followed was based on primary cystoscopy and valve ablation, with selective use of diversion procedures in complicated PUV. In cases that underwent initial diversion, the closure was done at 18-24 months of age. Cases managed by primary valve ablation (including intermediate and highrisk group) were followed-up with serial USS KUB, repeat VCUG and isotope renal scans, and check cystoscopy. The diagnosis of valve bladder syndrome was made during follow-up on the basis of persistent hydroureteronephrosis, abnormal bladder morphology on VCUG and Cystoscopy, the presence of urinary incontinence and polyuria, and findings of the urodynamic assessment, wherever feasible. In children who had undergone a preliminary diversion procedure, assessment for valve bladder syndrome was done after undiversion and ablation of the residual valve.

\section{Clinical classification of PUV}

The spectrum of PUV is characterized by variable severity of manifestations including posterior urethral and bladder changes, VUR, megaureter, renal dysplasia, and systemic sequelae. The entire spectrum of PUV is generally clubbed together under the same diagnostic umbrella, which undermines the basic variegated nature of the disorder. Any classification should recognize and segregate the variables to identify patients into subgroups of prognostic significance. The following classification is based on the clinical features and findings of investigations including serial VCUG, cystoscopy, ultrasound scan, renal function tests (RFT), and isotope studies (Table 1).

\section{Risk stratification in PUV}

Identification of poor risk cases at the very outset and monitoring them during follow-up can facilitate early initiation of corrective measures and more accurate prognostication. A risk stratification approach to supplement the clinical classification, which is primarily aimed at determining the risk of progression to ESRD, is being described here (Table 2).

\section{Results}

During the 5-year period, there were 102 cases (76 reviewed as retrospective and 26 studied as prospective) with an endoscopic diagnosis of PUV, which were selected 
Table 1 Clinical classification of PUV into distinct subgroups based on clinical criteria and response to therapy

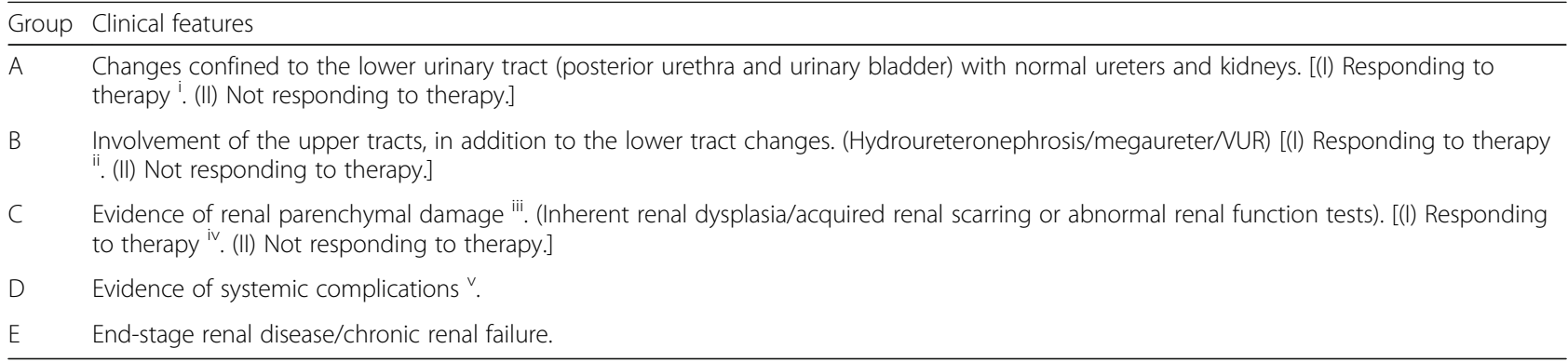

'Posterior urethral dilatation and bladder changes decreasing on serial VCUG and Cystoscopy

iiHydroureteronephrosis and/or VUR decreasing on serial investigations

iii Renal cortical thinning on USS, decreased cortical function on isotope study

${ }^{i v}$ Fall in elevated RFT, absence of progressive renal scarring

${ }^{\vee}$ Metabolic acidiosis/nephrogenic diabetes insipidus/hypertension/renal osteodystrophy/growth failure

for analysis. The primary objective was to assess the treatment received and complications during follow-up, with respect to the risk stratification employed. The cardinal results are summarized here (Tables $3,4,5,6,7,8$, and 9), as relevant to the risk stratification. The predominant clinical presentation was with antenatally detected fetal hydronephrosis in 78/102 cases (76\%), which were diagnosed as PUV during further evaluation and follow-up. Diagnosis in the rest of the 24 cases (24\%) was made postnatally during the evaluation of obstructive voiding symptoms, incidentally detected hydronephrosis or UTI.

The diagnosis of PUV was made, and the initial therapy was provided during infancy in the majority of cases $(83 \%)$ and most commonly in the neonatal period $(41 \%)$ (Table 3$)$. The patients were classified in one of the groups, based on the risk stratification guidelines. Patients were classified as low/ intermediate risk only if all criteria for the same were satisfied, whereas even a single-positive criterion would classify the patient as high risk. Twentyfive percent of the cases were classified as high risk (Table 4).
The clinical grouping at diagnosis and follow-up, including response to therapy, are summarized in Tables 5,6 , and 7 . The major therapeutic intervention adopted in the treatment was reviewed in each group, and it was noted that all major diversion procedures were done for the high-risk group, except for a single child with an intermediate risk who underwent a unilateral refluxing loop ureterostomy for recalcitrant UTI. The incidence of major complications during follow-up in each risk group was assessed individually and found to be greatest in the high-risk group (92\%), which was significantly higher than the other groups. The intermediate risk group was found to have a complication rate of $38 \%$, while the lowrisk group had the lowest complication rate of $12.5 \%$ (Tables 8 and 9).

\section{Discussion}

Hypothesis regarding the possible embryological basis of severity of PUV

The basic and cardinal error in development pertinent to PUV is the abnormal insertion and migration of the orifice of the mesonephric duct, which is a critical and

Table 2 Risk stratification approach to PUV; Risk strata to be assessed and recorded at diagnosis and during follow-up

\begin{tabular}{|c|c|c|c|}
\hline Criteria & Low risk & Intermediate risk & High risk \\
\hline $\begin{array}{l}\text { Posterior urethral dilatation; urinary } \\
\text { bladder changes }{ }^{1}\end{array}$ & $\begin{array}{l}\text { Posterior urethral dilatation present; } \\
\text { no bladder changes }\end{array}$ & Moderate to severe changes & Severe changes; persistent after therapy \\
\hline $\begin{array}{l}\text { Hydronephrosis/ } \\
\text { hydroureteronephrosis }\end{array}$ & Mild (no calyceal dilatation) & $\begin{array}{l}\text { Moderate (with calyceal } \\
\text { dilatation) }\end{array}$ & Severe (with cortical thinning) \\
\hline Vesicoureteric reflux & $\mathrm{Nil} /$ mild (grade 1/2) & Grade 3 & Grade 4/5 \\
\hline Features of valve bladder syndrome & Absent & Absent & Present \\
\hline Renal function tests & Normal & $\begin{array}{l}\text { Abnormal; normalizing with } \\
\text { therapy }\end{array}$ & Persistently abnormal \\
\hline Renal parenchymal involvement ${ }^{2}$ & Absent & $\begin{array}{l}\text { Unilateral, Mild }(<15 \%) \\
\text { functional deterioration }\end{array}$ & $\begin{array}{l}\text { Bilateral/moderate to severe (> 15\%) } \\
\text { functional deterioration }\end{array}$ \\
\hline Systemic complications ${ }^{3}$ & Absent & Absent & Present \\
\hline
\end{tabular}

${ }^{1}$ Based on VCUG and cystoscopy findings

${ }^{2}$ On isotope studies

${ }^{3}$ Metabolic acidosis/nephrogenic diabetes insipidus/hypertension/renal osteodystrophy/growth failure 
Table 3 Age at initial endoscopy and initiation of therapy

\begin{tabular}{ll}
\hline Age at initial endoscopy and therapy & $\boldsymbol{n}=102$ \\
\hline Less than 1 month & $42(41 \%)$ \\
$1-6$ months & $23(23 \%)$ \\
6 months-1 year & $19(19 \%)$ \\
$1-5$ years & $18(17 \%)$ \\
\hline
\end{tabular}

preliminary event in the development of the entire urogenital tract $[2,3]$. An error in this process can have widespread effects including (1) obstruction to the posterior urethra by mucosal folds (PUV), (2) abnormal development of the bladder and the hemitrigone, (3) abnormalities of the ureteral bud, and (4) abnormal induction of the metanephric blastema by the ureteral bud resulting in inherent renal dysplasia [2, 3, 4]. Hence, it can be hypothesized that the severity of the final pathology is determined by the following factors: (1) the extent of an initial developmental defect involving the mesonephric duct; (2) laterality of the abnormality-the pathology being less severe if the developmental error is unilateral and more severe if bilateral; (3) the type of abnormality in position of the ureteral bud and its faulty development from the mesonephric duct, (4) the extent of abnormality in development and absorption of the Common excretory duct, and (5) the extent of inherent renal dysplasia (Table 10).

The errors in cardinal developmental events would result in a major and variegated pathology, of which PUV can only be considered as a proverbial "tip of the iceberg." It would be logical to assume that the anomaly would be severe (and hence typical of the "classical PUV") if the development error is bilateral and atypical (and variable) where the defect is partial or unilateral. A relatively milder abnormality in development would result in mild changes in the bladder and urethra and mild hydronephrosis/VUR, with relatively normal kidneys. A more significant error in the development would result in moderate changes in the bladder and urethra and moderate hydronephrosis/ VUR with the presence of renal impairment. The most severe, bilateral developmental abnormality would lead to severe changes in the bladder and urethra, severe hydronephrosis/VUR, and severe renal dysplasia and further compounded by progressive renal scarring (Fig. 1)
Table 5 Clinical group of patients assigned at the time of diagnosis and initial therapy, based on clinical and investigation parameters

\begin{tabular}{ll}
\hline Clinical group & $n=102$ \\
\hline A & 18 \\
B & 34 \\
C & 40 \\
D & 10 \\
E & - \\
\hline
\end{tabular}

VURD syndrome: key to understanding the embryological basis of PUV

The commonly observed association of PUV with unilateral high-grade reflux into a dysplastic kidney is explained as one of the "pop-off" mechanisms, where the damage to the one kidney is protective to the other [5, 6]. This simple explanation could be true to the extent that high-grade reflux on the one side is protective to the other side during post natal life, by acting as a vent for the high bladder pressures in these children. But, this association could give practical clues to the embryogenesis of PUV. The more physiological way of analyzing this association is to infer that the process of mesonephric duct absorption, ureteral bud origin, absorption, and induction of metanephric blastema are grossly deranged only on one side. This results in unilateral severe reflux with renal dysplasia. The same developmental process on the opposite side is relatively normal, resulting in a properly functional, non-refluxing unit on that side. This would naturally dictate a better early prognosis, irrespective of the final outcome, which in turn depends on many other variables. The appearance of PUV in these cases may also not be classical on VCUG or cystoscopy, as the embryologic defect is unilateral/partial. It is equally significant that bilateral reflux in association with PUV, where both renal units are likely to be developmentally abnormal, clearly carries a worse prognosis [5, 6]. The severity of the embryological defect in a case of PUV can be assessed by considering the following factors: (1) Are the changes confined to the lower urinary tract or involve the upper tract? (2) Configuration of ureteric orifices and severity of VUR, if present. (3) Is the abnormality predominantly unilateral/Are both renal units involved? (4) Is there evidence of inherent renal dysplasia?

Table 4 Classification of patients based on the present risk stratification guidelines

\begin{tabular}{lr}
\hline Classification of patients based on the present risk stratification guidelines & $n=102$ \\
\hline Low risk & $24(24 \%)$ \\
Intermediate risk & $52(51 \%)$ \\
High risk & $26(25 \%)$ \\
\hline
\end{tabular}


Table 6 The major therapeutic intervention adopted in the cases of PUV

\begin{tabular}{lllll}
\hline $\begin{array}{l}\text { The major } \\
\text { therapeutic } \\
\text { intervention }\end{array}$ & $\begin{array}{l}\text { Total, } \boldsymbol{n} \\
=102\end{array}$ & $\begin{array}{l}\text { Low risk } \\
(\boldsymbol{n}=24)\end{array}$ & $\begin{array}{l}\text { Intermediate } \\
\text { risk }(\boldsymbol{n}=52)\end{array}$ & $\begin{array}{l}\text { High risk } \\
(\boldsymbol{n}=26)\end{array}$ \\
\hline $\begin{array}{l}\text { Cystoscopy and } \\
\text { valve ablation }\end{array}$ & 87 & 24 & 51 & 12 \\
$\begin{array}{l}\text { Ureterostomy } \\
\text { Unilateral }\end{array}$ & 13 & - & 1 & 12 \\
$\quad 3$ & - & 1 & 2 \\
$\begin{array}{l}\text { Bilateral } \\
\text { Vesicostomy }\end{array}$ & 10 & - & - & 10 \\
& 2 & - & - & 2
\end{tabular}

\section{The "posterior urethral valve sequence"}

Though the initial insult in PUV is developmental, the later picture is modified by various factors including changes of obstructive uropathy, maturation of the systems, and results of therapy. The posterior urethral dilatation and urinary bladder changes (including altered bladder morphology and bladder trabeculations) may improve or normalize after relief of distal obstruction. The grade of hydroureteronephrosis (HUN) and VUR may decrease after successful therapy $[6,7]$. Therefore, the changes associated with PUV in the lower and upper urinary tract are not static events, but dynamic phenomena related to the progression of disease and results of therapy $[8,9]$. It is also seen that some children who undergo urinary diversion (vesicostomy/ureterostomy) for complicated PUV have a significant early recovery with stabilization of renal function and relief of urinary sepsis. Irrespective of initial improvement, the risk of progression to ESRD remains high in this group. These instances highlight the deleterious secondary effects of obstructive uropathy, HUN, and VUR, which result in chronic pressure changes, valve bladder syndrome, and progressive renal scarring [8-10]. The "acquired" component of PUV should be identified and managed promptly, as this can be modified by therapy to improve outcome. Hence, it would be appropriate to consider PUV as the posterior urethral valve sequence characterized by congenital problems including (1) bladder

Table 7 Clinical grouping and reclassification of patients done during the follow-up at 6 months to 1 year after initial therapy

\begin{tabular}{lll}
\hline Clinical group at follow-up & $n=102$ & $\%$ \\
\hline A I & 14 & 13.7 \\
A II & 4 & 3.9 \\
B I & 24 & 23.5 \\
B II & 6 & 5.89 \\
C I & 32 & 31.3 \\
C II & 8 & 7.84 \\
D & 13 & 12.7 \\
E & 1 & 0.98 \\
\hline
\end{tabular}

Table 8 Incidence of complications during follow-up in each risk group

\begin{tabular}{ll}
\hline $\begin{array}{l}\text { Incidence of complications during follow-up in each risk } \\
\text { group }\end{array}$ & $\boldsymbol{n}=102$ \\
\hline Low risk & $3 / 24$ \\
& $(12.5 \%)$ \\
Intermediate risk & $20 / 52$ \\
& $(38 \%)$ \\
High risk & $24 / 26$ \\
& $(92 \%)$ \\
\hline
\end{tabular}

outlet obstruction; (2) changes in bladder and ureter, VUR; (3) inherent renal dysplasia; and acquired problems including (4) progressive vesical dysfunction, (5) megaureter with progressive renal scarring, and (6) metabolic and systemic complications [11-13].

The three key concepts addressed in this study pertain to the embryological basis of PUV, the necessity of a clinical subdivision of patients, and the possibility of risk stratification based on clinical criteria. The variable features were explained in terms of variations in the extent of the primary developmental error. The embryological correlation is helpful to evaluate the extent of initial developmental insult, which serves as a baseline data regarding the inherent urological issues and renal damage. While assessing the pathological features in these children, it is vital to understand the severity of the embryological error and determine the extent of affection to establish the severity of the disease. The "dynamic" nature of the findings in PUV was analyzed in the background of the evolving nature of the condition.

The limited review of institutional series is added to highlight the method of risk stratification and its probable utility. The analysis of the results of the series revealed that the need for major therapeutic interventions

Table 9 Incidence of sequelae in each risk group

\begin{tabular}{|c|c|c|c|}
\hline Major sequelae & $\begin{array}{l}\text { Low risk ( } \boldsymbol{n} \\
=24)\end{array}$ & $\begin{array}{l}\text { Intermediate risk } \\
(\boldsymbol{n}=52)\end{array}$ & $\begin{array}{l}\text { High risk* }(\boldsymbol{n} \\
=26)\end{array}$ \\
\hline Recurrent UTI & $2(8 \%)$ & $10(19 \%)$ & $8(31 \%)$ \\
\hline $\begin{array}{l}\text { Obstructive voiding } \\
\text { symptoms }\end{array}$ & $1(4 \%)$ & $12(23 \%)$ & $15(58 \%)$ \\
\hline $\begin{array}{l}\text { Persistent } \\
\text { hydronephrosis }\end{array}$ & $2(8 \%)$ & $18(34 \%)$ & $18(69 \%)$ \\
\hline Persistent VUR & - & $12(4 \%)$ & $14(54 \%)$ \\
\hline $\begin{array}{l}\text { Progressive renal } \\
\text { scarring }\end{array}$ & - & $9(17 \%)$ & $12(46 \%)$ \\
\hline Progressive uremia & - & $1(2 \%)$ & $12(46 \%)$ \\
\hline $\begin{array}{l}\text { Valve bladder } \\
\text { syndrome }\end{array}$ & - & $9(17 \%)$ & 18 (69\%) \\
\hline Systemic problems** & - & $1(2 \%)$ & $14(54 \%)$ \\
\hline
\end{tabular}


Table 10 Correlation of the developmental defect with resultant abnormality and possible clinical consequence

\begin{tabular}{|c|c|c|}
\hline Embryological/developmental defect & Resultant abnormality & Clinical consequence \\
\hline $\begin{array}{l}\text { Abnormal insertion and migration of the orifice } \\
\text { of the mesonephric duct }\end{array}$ & Posterior urethral valve & Obstructive uropathy \\
\hline $\begin{array}{l}\text { Abnormal development and absorption of the } \\
\text { 'Common excretory duct' }\end{array}$ & $\begin{array}{l}\text { Defective development of the } \\
\text { ipsilateral hemitrigone }\end{array}$ & $\begin{array}{l}\text { Abnormal "uretero-trigonal" mechanism with a } \\
\text { neuromuscular defect and abnormal vesicoureteric } \\
\text { junction (VUJ) }\end{array}$ \\
\hline $\begin{array}{l}\text { Abnormality in the position of the ureteral bud } \\
\text { and its development from the mesonephric duct }\end{array}$ & $\begin{array}{l}\text { Defect in the entire collecting system, } \\
\text { from the ureter to collecting tubules }\end{array}$ & $\begin{array}{l}\text { VUR and reflux nephropthy; ureteric obstruction; } \\
\text { hydroureteronephrosis; megaureter }\end{array}$ \\
\hline $\begin{array}{l}\text { Abnormal induction of the metanephric blastema } \\
\text { by the ureteral bud }\end{array}$ & Maldevelopment of the kidney & Inherent renal dysplasia \\
\hline
\end{tabular}

was more in the high-risk group. Individual complications in each risk group were categorized, and all major complications including persistent VUR, progressive renal scarring, valve bladder syndrome, and uremia were observed to be higher in the high-risk group. The available data revealed that the system of classification was helpful in establishing the prognosis at diagnosis and reviewing the results of therapy during follow-up. The description of the posterior urethral valve sequence is done with the objective of recognition of the disease as an entity with multiple variable manifestations that generally fits the description of a sequence.
The clinical classification aims to group the patients based on the extent of affection and response to therapy. This would serve to identify patients into separate subgroups of therapeutic and prognostic significance. The risk stratification approach supplements the clinical classification, by offering the option of applying different commonly used parameters to identify patients at high risk of ESRD. It is also equally important to anticipate, recognize, and treat systemic problems associated with PUV. The broad guidelines proposed for stratification can be modified or adapted based on additional, new, or evolving investigations and criteria. The essential aim of

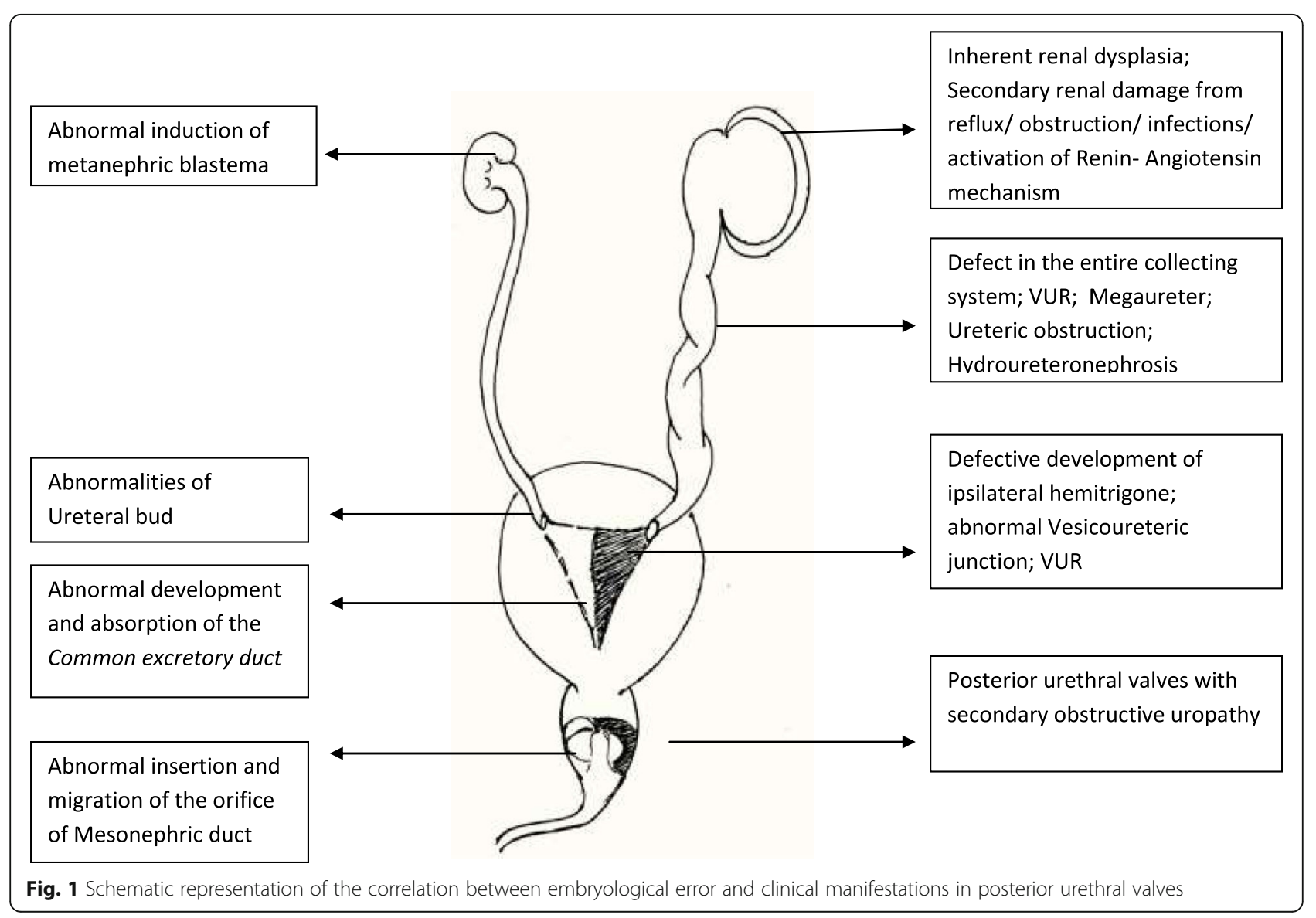


the system is to modulate therapy and follow-up based on the recognition of risk factors of progressive disease.

\section{Conclusion}

The most critical factors to be accounted for in the diagnosis and management of PUV are the definition of disease severity, recognition of systemic complications, and identification of children at risk of progression to ESRD. The proposed developmental defect analysis, the description of the PUV sequence, clinical classification, and risk stratification approach are only the means to this end of segregating patient groups within the diagnostic spectrum.

\section{Abbreviations}

PUV: Posterior urethral valves; USS KUB: Ultrasound scan of kidneys, ureters, and bladder; VUR: Vesicoureteral reflux; CRF: Chronic renal failure; ESRD: Endstage renal disease; HUN: Hydroureteronephrosis; UTI: Urinary tract infections; VCUG: Voiding cystourethrogram; RFT: Renal function tests; PRA: Plasma renin activity; VURD syndrome: Valves, unilateral reflux, and renal dysplasia

\section{Acknowledgements}

The sincere cooperation of all the faculty and residents in the department who contributed to the care of the patients is gratefully acknowledged.

\section{Authors' contributions}

The conceptualization, data collection, data analysis and final compilation of the article has been done by the author himself.

\section{Funding}

No funding was procured for this study.

\section{Availability of data and materials}

Available upon request.

\section{Ethics approval and consent to participate}

This article does not contain any studies with human participants or animals performed by the author. The study involved only chart review and analysis of routine preoperative, intraoperative, postoperative and follow up data of astandard surgical procedure, for which necessary institutional approval has been obtained. Standard institutional informed consent was obtained from all cases included in the study.

\section{Competing interest}

The author declares that there are no competing interests.

\section{Consent for publication}

The author gives consent for publication.

Received: 26 May 2020 Accepted: 26 June 2020

Published online: 27 August 2020

\section{References}

1. Caione P, Nappo SG. Posterior urethral valves: long-term outcome. PediatrSurg Int. 2011;27:1027-35. [PubMed] [Google Scholar].

2. Park JM. Normal development of the urogenital system. Wein et al. Campbell-Walsh Urology. 9. 2007. 4: 3121-48.

3. Brooks JD. Anatomy of the lower urinary tract and male genitalia. Wein et al. Campbell-Walsh Urology. 9. 2007. 1:38-77.

4. Glassberg, K. I. and Horowitz, M.: Urethral valves and other anomalies of the male urethra. In: Clinical Pediatric Urology, 4th ed. Edited by A. B. Belman, L. R. King and S. A. Kramer. London: Martin Dunitz Ltd., vol. 1, chapt. 28, pp. 899-945, 2002

5. Harrison MR, Filly RA, Parer JT, Faer MJ, Jacobson JB, de Lorimier AA, et al. Management of the fetus with a urinary tract malformation. JAMA. 1981; 246:635-9. [PubMed] [Google Scholar].
6. DeFoor W, Clark C, Jackson E, Reddy P, Minevich E, Sheldon C, et al. Risk factors for end stage renal disease in children with posterior urethral valves. J Urol. 2008;180:1705-8. [PubMed] [Google Scholar].

7. Heikkilä J, Rintala R, Taskinen S. Vesicoureteral reflux in conjunction with posterior urethral valves. J Urol. 2009;182:1555-60. [PubMed] [Google Scholar].

8. Ghanem MA, Wolffenbuttel KP, De Vylder A, Nijman RJ. Long-term bladder dysfunction and renal function in boys with posterior urethral valves based on urodynamic findings. J Urol. 2004;171:2409-12. [PubMed] [Google Scholar].

9. Haecker FM, Wehrmann M, Hacker HW, Stuhldreier G, von Schweinitz D. Renal dysplasia in children with posterior urethral valves: a primary or secondary malformation? PediatrSurg Int. 2002;18:119-22. [PubMed] [Google Scholar].

10. Menon P, Rao KL, Vijaymahantesh S, Kanojia RP, Samujh R, Batra YK, et al. Posterior urethral valves: morphological normalization of posterior urethra after fulguration is a significant factor in prognosis. J Indian Assoc Pediatr Surg. 2010;15:80-6. [PMC free article] [PubMed] [Google Scholar].

11. Desai DY. A review of urodynamic evaluation in children and its role in the management of boys with posterior urethral valves. Indian J Urol. 2007;23: 435-42. [PMC free article] [PubMed] [Google Scholar].

12. Thomas J. Etiopathogenesis and management of bladder dysfunction in patients with posterior urethral valves. Indian J Urol. 2010;26:480-9. [PMC free article] [PubMed] [Google Scholar].

13. Otukesh H, Sharifiaghdas F, Hoseini R, Fereshtehnejad SM, Rabiee N, Kiaiee $M F$, et al. Long-term upper and lower urinary tract functions in children with posterior urethral valves. J Pediatr Urol. 2010;6:143-7. [PubMed] [Google Scholar].

\section{Publisher's Note}

Springer Nature remains neutral with regard to jurisdictional claims in published maps and institutional affiliations.

\section{Submit your manuscript to a SpringerOpen ${ }^{\circ}$ journal and benefit from:}

- Convenient online submission

- Rigorous peer review

- Open access: articles freely available online

- High visibility within the field

- Retaining the copyright to your article

Submit your next manuscript at $\boldsymbol{\nabla}$ springeropen.com 